\title{
Knowledge, awareness, and attitudes to breast cancer among school teachers in Kaduna Metropolis, Kaduna State, Nigeria
}

\author{
Solomon Tabat Yaya ${ }^{1}$, Asmaa Mahmoud Abuaisha ${ }^{2}$, Joseph Gyutorwa Samson ${ }^{3}$, Nedime Serakinci, ${ }^{4,5}, *$
}

${ }^{1}$ Near East University, Institute of Health Sciences, Department of Medical Biology and Genetics, Turkish Republic of Northern Cyprus

${ }^{2}$ Near East University, Institute of Health Sciences, Department of Medical Genetics, Turkish Republic of Northern Cyprus

${ }^{3}$ Kaduna State University, Department of Biological Sciences, Nigeria

${ }^{4}$ Near East University, Faculty of Medicine, Department of Medical Biology and Genetics, Nicosia, Turkish Republic of Northern Cyprus

${ }^{5}$ Near East University, Faculty of Art and Sciences, Department of Molecular Biology and Genetics, Nicosia, Turkish Republic of Northern Cyprus

\section{Correspondence}

Nedime Serakinci, Near East University, Faculty of Medicine, Department of Medical Biology and Genetics, Nicosia, Turkish Republic of Northern Cyprus

Near East University, Faculty of Art and Sciences, Department of Molecular Biology and Genetics, Nicosia, Turkish Republic of Northern Cyprus

Email: nedimeserakinci@gmail.com

History

- Received: 03 October 2018

- Accepted: 01 November 2018

- Published: 19 November 2018

DOI :

https://doi.org/10.15419/ajhs.v4i2.439

\section{Check for updates}

Copyright

(c) Biomedpress. This is an openaccess article distributed under the terms of the Creative Commons Attribution 4.0 International license.

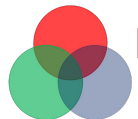

BioMedPress

The Open Access Publisher

\begin{abstract}
Objectives: To investigate the knowledge, awareness, and attitudes of school teachers towards breast cancer in Kaduna metropolis. Methods: A survey of school teachers aged 20 - 65 years was conducted in both public and private schools in Kaduna metropolis. A self-administered questionnaire was used to collect the data. Results: Out of the 997 participants, mean age 40.69 (SD = 12.09) years. Of all the participants, 259 (26.0\%) were males, and 738 (74.0\%) were females. The role of a teacher in disseminating information or knowledge cannot be overemphasized. Because of that crucial role they play thus makes it necessary that they have the right information so that they can transfer such to their students or wards. The children today represents the young generation that is growing. It will be good if they have the right knowledge about breast cancer concerning what breast cancer is, what causes it, knowledge of signs and symptoms, and what measures to take to prevent or treat it. Conclusion: This study shows that there is breast cancer awareness but there is low in-depth knowledge about the disease. There is low knowledge of risk factors, signs and symptoms, low response to breast self-examination (BSE), clinical breast examination (CBE) and mammography. Educational health programs can be organized to help create more awareness and knowledge about breast cancer which has the potential to help the public in making informed decisions thereby reducing the incidence of this disease.
\end{abstract}

Key words: Knowledge, Awareness, Attitudes, Breast cancer, Risk factors

\section{INTRODUCTION}

According to the 2014 World Health Organization (WHO) report, among other causes of deaths worldwide, $14.6 \%$ of deaths are as a result of a variety of cancer types. In many, breast cancer is one of the leading malignant neoplasms in women. Breast cancer compared with cervix cancer leads to more deaths, about three times more often, affecting women of ages 15 to 50 years $^{1}$.

In Nigeria, breast cancer among women is also the leading cause of cancer death with the highest age of occurrence between the ages of 30 to 40 years which develops ten years earlier before estimated time compared to the Caucasians. The survival rate of a cancer patient within five years is below $10 \%$ when compared with above $70 \%$ in the Western European and North America ${ }^{2}$.

To reduce the rate of death caused by cancer, it is very important to adopt preventive behaviors. An invaluable tool to achieve this change in behavior is knowledge. Women need to be educated with regards to signs that may serve as early diagnostic warnings and symptoms, which will cause them to habitually go for improved health seeking. This awareness creation is vital to basically reducing the high incidence and death rate for breast cancer disease ${ }^{3}$.

Breast cancer even though is rare in males; they also can be affected with breast cancer ${ }^{4}$. It is important to use education and considering the different cultural backgrounds with the aim of targeting such individuals in a population thereby achieving maximum gain and not neglecting the importance of educating men alongside women, being that men can contribute to early detection in their partner which will cause them to seek for medical care early. It is also vital to create awareness but more importantly spreading the knowledge with regards to the fact that breast cancer can be cured, if the nature and cause of it are considered early, the patient will have a good chance of survival ${ }^{5}$. The differences in people's belief systems and misconception including many factors as education, ethnicity, and age also affect their attitudes ${ }^{6}$.

Women need to be 'breast aware' and quite necessary to have the ability to identify signs and symptoms of mammary cancer by periodically carrying out checks which will enable them to seek medical help on time. Death due to mammary cancer among Nigerian women is as a result of late admittance of medical assistance basically until the late onset of the disease $^{7}$. Late diagnosis of mammary cancer patients is 
the cause of reduced survival rate ${ }^{8}$.

There is serious need to create awareness since patients usually present late in hospitals or clinics for diagnosis for breast cancer. Measures that have been advised to prevent and reduce mammary cancer death and pains are; Breast Self-Examination (BSE), Mammography, and Clinical Breast Examination (CBE) ${ }^{9}$. To prevent and reduce problems and impairment, mammary cancer that is detected on time is promising toward diagnosis and treatment ${ }^{10}$.

In the world, an unlikely disease of men is the male mammary cancer which is diagnosed at a percentage less than one among all breast cancer ${ }^{11}$, this is less compared to the earlier estimation ${ }^{12}$, and the yearly occurrence rate is predicted at 1 person in every 100,000 men in the world ${ }^{13}$. One person in 1000 men has a risk of developing breast cancer in his lifetime, 60 and 70 is the mean age of male cancer examination with frequency rate increasing in a straight line with age $^{14}$. Male breast cancer also is an issue pointing to genetics as a contributor after considering a male with a family history of breast cancer. This put such a male on a high-risk of developing breast cancer in his lifetime ${ }^{15,16}$.

There is the possibility of preventing more than 50 percent of cancer morbidity and mortality in the entire world due to the fact that most of the liable causes of cancer are jointly related which can be changed and averted ${ }^{17}$. These manageable risk factors include vital nutrition deficiency, inactive lifestyle, obesity, smoking, alcohol consumption, and sexually transmitted infections such as the Human Papilloma Virus $(\mathrm{HPV})^{18}$.

If one has the knowledge and understanding of the risks or liable causes of cancer, this will immensely help in causing the person to make informed and conscious decisions to take part in prevention and screening actions. It has been advised that increased knowledge and awareness levels are linked with the right attitudes towards cancer ${ }^{18}$. Having this knowledge and awareness leads to demonstrate a positive attitude when faced with the disease ${ }^{19}$.

There are still more people who have poor attitudes and practices towards the prevention of this disease. Besides, tackling the changeable risk factors, screening for cancer was listed as a secondary prevention measure. Studies previously have proved the effectiveness of cancer screening in cancer death rate reduction $^{20}$.

The increasing tendencies of breast cancer in developing areas is often treated generally by saying it is because of 'westernization' of lifestyle in such areas, an unclear proxy for factors such as dietary habits, childbearing, exposure to exogenic estrogen hormones, reaching a circulation closer in a sketch compared to women in industrialized countries ${ }^{21}$.

No work has been done on the topic Knowledge, Awareness and Attitudes towards Breast Cancer among School Teachers in the metropolitan part of Kaduna state and therefore we can say that this research is timely seeing the fast rate at which breast cancer has and is becoming a global problem in developed and developing countries respectively.

It is true that teachers play a vital and effective part in communicating and motivating young generations. This research undertaken to assess their knowledge, awareness, and attitudes is paramount to breast cancer reduction in our young generation. Notwithstanding, practicing any of the breast cancer screening methods depends on the awareness and knowledge level of an individual. If teachers have poor knowledge and awareness level about breast cancer, challenges will be encountered in upholding these lifesaving techniques which include BSE, CBE, and mammography. This is because they will not practice the methods. Male gender is often excluded in most studies but this research included both genders.

This study is devised to carry out evaluation on the knowledge, awareness, and attitudes towards breast cancer among school teachers in Kaduna metropolis so that the result will be used to develop possible national education program for schools and communities, also to find out if there is a significant difference between the ages of teachers and their level of breast cancer knowledge. We hypothesize that breast cancer incidence can be reduced by increasing the awareness and knowledge of signs and symptoms in Kaduna metropolis, also teachers' level of knowledge and attitudes has a significant role in reducing breast cancer.

\section{METHODS}

A cross-sectional survey was carried out from the month of February to the month of May 2017 in the Kaduna metropolis, Kaduna State, Nigeria. A total of 1100 school teachers in both public and private schools (Primary and Secondary) with the ability to understand the structured questionnaire were recruited to take part in the research. A verbal permission was sought from the teachers who wished to participate in the research, and they were assured that their individual responses will be kept private before questionnaires were administered.

\section{Materials}

The materials that were used for this research were self-administered questionnaires (see appendix 1 ). 


\section{Study Area}

The study area is located in Kaduna state which is one of the 36 states in Nigeria including the Federal Capital Territory (FCT) Abuja. There are 23 local governments in this state. According to the Nigerian census Figure in 2006, the state has a population of about 6.3 million people in 2006. Kaduna is the capital city of the state. The state has a total area of 17,781 square miles $(46,053 \mathrm{kmsq})$ and its coordinates are $10^{\circ} 20^{\prime} 0^{\prime \prime} \mathrm{N}^{\prime} 7^{\circ} 45^{\prime} 0^{\prime \prime} \mathrm{E}$. There are over 60 ethnic groups which include Hausa, Gbagyi, Fulani, Gwong, Atuku, Bajju, Atyab, Gure, Kagoro, Adara and among others that populate Kaduna State. This region of the country is a major economic hub, a center for trade and a transport axis to nearby agricultural areas and states. Kaduna is an industrial center of Northern Nigeria (Kaduna State Government, 2017). Kaduna city is the metropolitan area where this study was conducted in different schools.

\section{Data Analysis}

Data were analyzed using Statistical Package for Social Sciences (SPSS) Version 18. Categorical variables were described using descriptive statistics of frequencies and percentages. Chi-square was used to test for significance using a $p$-value of 0.05 .

\section{RESULTS}

The total number of participants is 997 . The age at the time of data collection ranged from 20 to above 50 years with a mean age of $40.69(S D=12.09)$ years. Of all the participants, 259 (26.0\%) were males and $738(74.0 \%)$ were females (Table 1 ).

The highest number of age groups are those who are [ $>50$ ] years with a frequency of 307 (30.8\%) of all the participants, followed by [40 - 49] 275(27.6\%) then [20 - 29] is $218(21.9 \%)$ and the lowest is [30 - 39] $197(21.9 \%)$. In terms of the level of education, 855 $(85.8 \%)$ have an academic degree, $134(13.4 \%)$, attended secondary school and $8(0.8 \%)$ attended primary school.

Based on their ethnicity, 'Hausa' had a frequency of 179 (18.0\%), 'Igbo' 152 (15.1\%), Yoruba 91 (9.1\%) and 'Other' ethnic groups (Chawai, Jaba (Ham), Kagoma (Gwong), Moro'a, Fulani, Katab (Atyab), Bajju, Gbagyi, Kadara (Adara), Kamantan, Kuturmi, Ikulu, Kagoro (Oegworok), Koro, Numana, Nandu, Ninzom, Atakar (Takad), Koninkon, and Delta) were the highest put together with a frequency of 575 (57.7\%). The title 'Others' under the ethnic groups makes the highest population which also reveals the multi-ethnicity of Kaduna State as a whole. Notwithstanding, they consisted of small percentages put together that gave this high number which makes it seems larger than the major ethnic groups Hausa, Yoruba and Igbo put together (Table 1).

There were 8 participants that had a primary level of education and 134 had secondary education this can be explained by the age of children that they are taking care of (Table 1). For example, those that assist in taking care of kindergartens and also some teachers who had a secondary level of education were employed by private primary schools while waiting for admission into higher institutions. This coupled with the fact that some private schools source for cheap labor from such teachers. More than half 540 (54.2\%) of the participants are married (Table 1).

Both males 78 (34.5\%) and females 148 (65.5\%) indicated social media which is the highest as their source of breast cancer information which shows the power of social media in disseminating information (Table 2). The least source of breast cancer information is religious forum 8 (3.1\%) and journal 13 (1.8\%) for both male and female respectively (Table 2).

Those that claimed to have an affected family member are $8(3.1 \%)$ among the males and $27(3.7 \%)$ among the females. $13(1.8 \%)$ females and $5(1.9 \%)$ males claimed to have survived breast cancer (Table 3 ).

A total of 329 (44.6\%) of females claimed to have a moderate knowledge of breast cancer which is higher than the males where about 106 (40.9\%) said they have low knowledge about the disease Table 4. At a $p$ value of 0.0068 which is less than $\alpha$ value (0.05), this indicates that there is a statistically significant difference between gender and level of knowledge of breast cancer (Table 4).

One hundred and four (55.0\%) of female participants within the age range of 40 to 49 claimed to have moderate knowledge about breast cancer which is the highest among the female age groups. The $p$-value of $<0.05$ indicated significance in this result (Table 5).

Across all ages of males majority claimed to have the low level of breast cancer knowledge except 30 to 39 age range $24(46.2 \%)$ that claimed to have high knowledge about the disease. There is a statistical significant difference since the $p$-value is $<0.05$ (Table 6).

Majority of the participant was positive that breast cancer could be inherited (Table 7) which is right for people who have a BRCA1 and BRCA2 mutation pathogenic carriers ${ }^{22-24}$. It was also observed that the majority of females $64.6 \%$ identified oral contraceptive use as a risk factor (Table 7). The use of oral contraceptives for a long time has been linked with a small increase in breast cancer risk among young women ${ }^{25}$. 
Table 1: Demographic characteristics of the study participants

\begin{tabular}{|c|c|c|}
\hline Variable & Frequency & Percentage (\%) \\
\hline \multicolumn{3}{|c|}{ Age groups (Years) } \\
\hline $20-29$ & 218 & 21.9 \\
\hline $30-39$ & 197 & 19.8 \\
\hline $40-49$ & 275 & 27.6 \\
\hline$>50$ & 307 & 30.8 \\
\hline \multicolumn{3}{|l|}{ Gender } \\
\hline Male & 259 & 26.0 \\
\hline Female & 738 & 74.0 \\
\hline \multicolumn{3}{|c|}{ Educational level } \\
\hline Primary & 8 & 0.8 \\
\hline Secondary & 134 & 13.4 \\
\hline Tertiary & 855 & 85.8 \\
\hline \multicolumn{3}{|c|}{ Marital Status } \\
\hline Single & 240 & 24.1 \\
\hline Married & 540 & 54.2 \\
\hline Divorced & 65 & 6.5 \\
\hline Widowed & 152 & 15.2 \\
\hline \multicolumn{3}{|l|}{ Ethnicity } \\
\hline Hausa & 179 & 18.0 \\
\hline Yoruba & 91 & 9.1 \\
\hline Igbo & 152 & 15.2 \\
\hline Others & 575 & 57.7 \\
\hline
\end{tabular}

There is a statistically significant difference between participants that identified breastfeeding, obesity, oral contraceptive use, and trauma to the breast as risk factors compared to participants that are on the contrary (Table 7). More so, between those that identified breast cancer can be inherited, null parity, smoking, and consanguinity showed no statistically significant difference (Table 7).

One hundred and ninety (73.4\%) male and 555 (75.2\%) female participants have not had a diagnostic testing, $164(63.3 \%)$ males and 425 (57.6\%) females do not know how to carry out BSE, 180 (69.5\%) males and 498 (67.5\%)females have not done CBE, and $208(80.3 \%)$ male and $600(81.3 \%)$ females have not carried out mammography (Table 8). $61.0 \%$ of females and $66.0 \%$ of males have not practiced BSE. This result showed no statistically significant difference (Table 8).
The female ages according to their responses to the screening tests show no significant difference (Table 9).

The only not statistically significant difference observed in males is among those that responded to BSE with a p-value of 0.067 but the rest are significant (Table 10).

Regarding the treatment for breast cancer, 78 (30.1\%) males and $204(27.6 \%)$ of females think that breast cancer can be cured using alternative or herbal medicine because it is thought to be effective and beneficial (Table 11). On the contrary, 181 (25.3\%) of male and $534(74.7 \%)$ of female participants disagreed because according to them it has not been proven, cancer has no known cure, and that a patient still died after the herbal medicine was administered (Table 11). Our result indicates no statistically significant difference because all the $p$-values are greater than 0.05 (Table 11). 
Table 2: Source of breast cancer knowledge of participants stratified by gender

Male $(\mathbf{n}=259) \quad$ Female $(\mathbf{n}=738)$

Source of breast cancer information

Physician/health worker

$19(7.3 \%) \quad 19(7.3 \%)$

Seminar/workshop

$15(5.8 \%) \quad 58(7.9 \%)$

Radio/TV

$39(15.1 \%) \quad 146(19.8 \%)$

Newspaper

$23(8.9 \%)$

$35(4.7 \%)$

Friends

$34(13.1 \%)$

$101(13.7 \%)$

Religious forum

$8(3.1 \%)$

$23(3.1 \%)$

Social media

$78(30.1 \%)$

$148(20.1 \%)$

Non-Governmental Organization

$17(6.6 \%)$

$109(10.9 \%)$

Family

$16(6.2 \%)$

47 (6.4\%)

Journals

$10(3.9 \%)$

$23(2.3 \%)$

Please note that some participants indicated multiple sources of breast cancer information n=number

Table 3: Participants with family history/once had breast cancer stratified by gender

\begin{tabular}{llccc}
\hline & \multicolumn{2}{c}{ Gender } & p-value \\
& & Male $(\mathbf{n}=\mathbf{2 5 9})$ & Female (n= 738) & \\
Affected family member & Yes & $8(3.1 \%)$ & $27(3.7 \%)$ & 0.668 \\
& No & $251(96.9 \%)$ & $711(96.3 \%)$ & \\
Once had breast cancer & Yes & $5(1.9 \%)$ & $13(1.8 \%)$ & 0.861 \\
& No & $254(98.1 \%)$ & $725(98.2 \%)$ & \\
\hline
\end{tabular}

Table 4: Level of breast cancer knowledge of participants stratified by gender

\begin{tabular}{lccc}
\hline & Male $(\mathbf{n}=\mathbf{2 5 9})$ & Female $(\mathbf{n}=\mathbf{7 3 8})$ & p-value \\
Knowledge level & & & \\
Low & $106(40.9 \%)$ & $249(33.7 \%)$ & $0.0068^{*}$ \\
Moderate & $86(33.2 \%)$ & $329(44.6 \%)$ & \\
High & $67(25.9 \%)$ & $160(21.7 \%)$ & \\
\hline
\end{tabular}

Table 5: Level of breast cancer knowledge of participants stratified by ages of females

\begin{tabular}{|c|c|c|c|c|c|c|}
\hline & & & Age n (\%) & & Total & p-value \\
\hline $\begin{array}{l}\text { Breast cancer knowledge } \\
\text { level }\end{array}$ & $20-29$ & $30-39$ & $40-49$ & $50-65$ & & \\
\hline Low & $77(43.3)$ & $42(29.0)$ & $66(34.9)$ & $64(28.3)$ & $249(33.7)$ & \\
\hline Moderate & $60(33.7)$ & $66(45.5)$ & $104(55.0)$ & $99(43.8)$ & 329 (44.6) & $<0.05^{\star}$ \\
\hline High & $41(23.0$ & 37 (25.5) & $19(10.1)$ & $63(27.9)$ & 160 (21.7) & \\
\hline
\end{tabular}




\begin{tabular}{|c|c|c|c|c|c|c|}
\hline \multirow{2}{*}{$\begin{array}{l}\text { Breast cancer knowledge } \\
\text { level }\end{array}$} & \multicolumn{3}{|c|}{ Age n (\%) } & & \multirow[t]{2}{*}{ Total } & \multirow[t]{2}{*}{ p-value } \\
\hline & $20-29$ & $30-39$ & $40-49$ & $50-65$ & & \\
\hline Low & $17(42.5)$ & $16(30.8)$ & $40(46.5)$ & $33(40.7)$ & $106(40.9)$ & \\
\hline Moderate & $14(35.0)$ & $12(23.0)$ & $38(44.2)$ & $22(27.2)$ & $86(33.2)$ & $<0.05^{*}$ \\
\hline High & $9(22.5)$ & $24(46.2)$ & $8(9.3)$ & $26(38.8)$ & $67(25.9)$ & \\
\hline
\end{tabular}

Table 7: Knowledge of breast cancer risk factors of participants stratified by gender

\begin{tabular}{|c|c|c|c|c|}
\hline & & Male $(n=259)$ & Female $(n=738)$ & P-value \\
\hline \multirow{2}{*}{$\begin{array}{l}\text { Breast cancer can be } \\
\text { inherited }\end{array}$} & Yes & $215(83.0 \%)$ & $647(87.7 \%)$ & \multirow{2}{*}{0.059} \\
\hline & No & $44(17.0 \%)$ & $91(12.3 \%)$ & \\
\hline \multirow{2}{*}{ Breast feeding } & Yes & $157(60.6 \%)$ & $572(77.5 \%)$ & \multirow{2}{*}{$<0.001^{*}$} \\
\hline & No & $102(39.4 \%)$ & $166(22.5 \%)$ & \\
\hline \multirow{2}{*}{ Null parity } & Yes & $126(48.6 \%)$ & $404(54.7 \%)$ & \multirow{2}{*}{0.091} \\
\hline & No & $133(51.4 \%)$ & $334(45.3 \%)$ & \\
\hline \multirow{2}{*}{ Obesity } & Yes & $91(35.1 \%)$ & $382(51.8 \%)$ & \multirow{2}{*}{$<0.001^{*}$} \\
\hline & No & $168(64.9 \%)$ & $356(48.2 \%)$ & \\
\hline \multirow{2}{*}{ Oralcontraceptives } & Yes & $153(59.1 \%)$ & $644(64.6 \%)$ & \multirow{2}{*}{$0.031^{*}$} \\
\hline & No & $106(40.9 \%)$ & $353(35.4 \%)$ & \\
\hline \multirow{2}{*}{ Trauma } & Yes & $149(57.5 \%)$ & $479(64.9 \%)$ & \multirow{2}{*}{$0.034^{*}$} \\
\hline & No & $110(42.5 \%)$ & $259(35.1 \%)$ & \\
\hline \multirow[t]{2}{*}{ Smoking } & Yes & $145(56.0 \%)$ & $452(61.2 \%)$ & \multirow{2}{*}{0.137} \\
\hline & No & $114(44.0 \%)$ & $286(38.8 \%)$ & \\
\hline
\end{tabular}

One hundred and forty-one $(54.1 \%)$ of males and $371(50.3 \%)$ which makes the majority of the participants denied the possibility of a breast cancer sign when they observe a painless lump (Table 12). Although not all lumps on breast lead to breast cancer notwithstanding, it is also an important indicator. 200 (77.2\%) of the males and 584 (79.1\%) females said that they will visit a doctor if they observed a blood discharge from their breast (Table 12). Having such attitude of seeking for medical help from the physicians or medical doctors will enable early detection and diagnosis of breast cancer.

Seventy-five (29.0\%) males and 241 (32.1\%) female participants said lack of awareness is the reason why they do not go for cancer screening which is the highest followed by the fear of a positive result having 68 (26.3\%) males and 143 (19.4\%) females. The least is participants that answered 'no reason' making 15 (5.8\%) males and 26 (3.5\%) females (Table 13). A pvalue of 0.015 shows a statistically significant differ- ence in this result (Table 13).

Two hundred and ten (81.9\%) males and 552 (74.8\%) female participants did not believe that breast cancer is caused by magic or evil spirits, also 183 (70.7\%) males and 487 (66.0\%) said that breast cancer is not contagious (Table 14).

The participants are positive about including the breast cancer awareness in the school curriculum looking at the $737(73.9 \%)$ of those who agree as against 260 (26.1\%) who do not agree (Table 15).

A $p$-value of 0.085 and 0.718 under inclusion in the school curriculum and sufficient breast cancer awareness in Nigeria respectively shows no statistically significant difference (Table 15). But the question that asked if breast cancer is a major problem in Nigeria shows significance at a $p$-value of 0.005 (Table 15).

There is a higher mortality rate due to breast cancer among the Sub-Saharan women compared to the women in the Western world; however Western women have a much higher incidence rate of the 


\begin{tabular}{|c|c|c|c|c|}
\hline & & Male $(n=259)$ & Female $(n=738)$ & p-value \\
\hline \multirow[t]{2}{*}{ Diagnostic Test } & Yes & $69(26.6 \%)$ & $183(24.8 \%)$ & \multirow[t]{2}{*}{0.557} \\
\hline & No & $190(73.4 \%)$ & $555(75.2 \%)$ & \\
\hline \multirow[t]{2}{*}{ BSE } & Yes & $95(36.7 \%)$ & $313(42.2 \%)$ & \multirow[t]{2}{*}{0.106} \\
\hline & No & $164(63.3 \%)$ & $425(57.6 \%)$ & \\
\hline \multirow[t]{2}{*}{ Practice of BSE } & Yes & $87(33.6 \%)$ & $260(35.2 \%)$ & \multirow[t]{2}{*}{0.634} \\
\hline & No & $172(66.4 \%)$ & $478(64.8 \%)$ & \\
\hline \multicolumn{5}{|l|}{ How often (BSE) } \\
\hline Never & & $172(66.4 \%)$ & $478(64.8 \%)$ & \multirow{3}{*}{0.634} \\
\hline Monthly & & $52(20.1 \%)$ & $161(21.8 \%)$ & \\
\hline Yearly & & $35(13.5 \%)$ & $99(13.4 \%)$ & \\
\hline \multirow[t]{2}{*}{$\mathrm{CBE}$} & Yes & $79(30.5)$ & $240(32.5 \%)$ & \multirow[t]{2}{*}{0.549} \\
\hline & No & $180(69.5 \%)$ & $498(67.5 \%)$ & \\
\hline \multicolumn{2}{|l|}{$\begin{array}{l}\text { How often (CBE) } \\
\text { Never }\end{array}$} & $180(69.5 \%)$ & $498(67.5 \%)$ & \\
\hline \multicolumn{2}{|l|}{ Once } & $14(5.4 \%)$ & $79(10.7 \%)$ & \\
\hline \multicolumn{2}{|l|}{ Twice } & $63(24.3 \%)$ & $151(20.5 \%)$ & \multirow{2}{*}{0.549} \\
\hline$>3$ times & & $2(0.8 \%)$ & $10(1.4 \%)$ & \\
\hline \multirow[t]{2}{*}{ Mammography } & Yes & $51(19.7 \%)$ & $138(18.7 \%)$ & \multirow[t]{2}{*}{0.726} \\
\hline & No & $208(80.3 \%)$ & $600(81.3 \%)$ & \\
\hline \multicolumn{5}{|c|}{ How often (mammography) } \\
\hline Never & & $208(80.3 \%)$ & $600(81.3 \%)$ & \multirow{4}{*}{0.726} \\
\hline Once & & $2(0.8 \%)$ & $10(1.4 \%)$ & \\
\hline Twice & & $22(8.5 \%)$ & $62(8.4 \%)$ & \\
\hline$>3$ times & & $27(10.4 \%)$ & $66(8.9 \%)$ & \\
\hline
\end{tabular}

disease ${ }^{26,27}$. The type of breast cancer that African women develop is the more aggressive type and the cause of the high death rate has been associated with the lack of public awareness of breast cancer generally. Also, the screening programs are limited which usually lead to late diagnosis of the disease even at its metastatic stage to other organs ${ }^{28}$.

It was observed that a lower number and a higher percentage of males 5 (1.9\%)compared to females but a higher number and lower percentage of females 13 (1.8\%) claimed to have had breast cancer (Table 3 ). This could be due to the method of recruitment of study participants which was not random coupled with the fact that some participants may not have understood the question. Furthermore, of all the participants, the females consist of $74.0 \%$ and males $26.0 \%$.
It is known that women have a higher percentage of breast cancer compared to men. In response to the name of a type of cancer that a family member might have suffered other than breast cancer, a participant named adamantinoma cancer which is a rare primary low-grade bone malignant tumor of which the histogenesis is not known and is mostly found in the mid part of the tibia ${ }^{29}$. The breast cancer disease killed most affected known persons in this study as claimed by the participants willingly added this information.

Campaigns have begun in recent years by the World Health Organization (WHO) with several local and international organizations to create more awareness of the disease among women in the Sub-Sahara African region. Because breast cancer develops in African women reaching a peak of 10 years earlier be- 
Table 9: Breast cancer examination and screening stratified by ages of females

\begin{tabular}{|c|c|c|c|c|c|c|c|}
\hline & & \multicolumn{4}{|c|}{ Age } & \multirow{2}{*}{ Total } & \multirow[t]{2}{*}{ p -value } \\
\hline & & $20-29$ & $30-39$ & $40-49$ & $50-65$ & & \\
\hline \multirow[t]{2}{*}{ Diagnostic Test } & Yes & 30 & 25 & 36 & 92 & 183 & $<0.001^{*}$ \\
\hline & No & 148 & 120 & 153 & 134 & 555 & \\
\hline \multirow[t]{2}{*}{ BSE } & Yes & 53 & 48 & 94 & 118 & 313 & $<0.001^{*}$ \\
\hline & No & 125 & 97 & 95 & 108 & 425 & \\
\hline \multirow{3}{*}{$\begin{array}{l}\text { How often } \\
\text { (BSE) }\end{array}$} & Never & 137 & 101 & 98 & 114 & 450 & $<0.001^{*}$ \\
\hline & Monthly & 26 & 22 & 69 & 60 & 177 & \\
\hline & Yearly & 15 & 22 & 22 & 52 & 111 & \\
\hline \multirow[t]{2}{*}{ CBE } & Yes & 32 & 32 & 76 & 100 & 240 & $<0.001^{*}$ \\
\hline & No & 146 & 113 & 113 & 126 & 498 & \\
\hline \multirow{4}{*}{$\begin{array}{l}\text { How often } \\
\text { (CBE) }\end{array}$} & Never & 146 & 110 & 113 & 126 & 495 & $<0.001^{*}$ \\
\hline & Once & 18 & 23 & 27 & 14 & 82 & \\
\hline & Twice & 14 & 12 & 39 & 86 & 151 & \\
\hline & $<3$ times & 0 & 0 & 10 & 0 & 10 & \\
\hline \multirow[t]{2}{*}{ Mammography } & Yes & 0 & 6 & 40 & 92 & 138 & $<0.001^{*}$ \\
\hline & No & 178 & 139 & 149 & 134 & 600 & \\
\hline \multirow{4}{*}{$\begin{array}{l}\text { How often } \\
\text { (mammogra- } \\
\text { phy) }\end{array}$} & Never & 178 & 139 & 149 & 132 & 598 & $<0.001^{*}$ \\
\hline & Once & 0 & 0 & 10 & 0 & 10 & \\
\hline & Twice & 0 & 6 & 10 & 46 & 62 & \\
\hline & $<3$ times & 0 & 0 & 20 & 48 & 68 & \\
\hline
\end{tabular}

Table 10: Breast cancer examination and screening stratified by ages of males

\begin{tabular}{|c|c|c|c|c|c|c|c|}
\hline & & \multicolumn{4}{|c|}{ Ages } & \multirow[t]{2}{*}{ Total } & \multirow[t]{2}{*}{ p-value } \\
\hline & & $20-29$ & $30-39$ & $40-49$ & $50-65$ & & \\
\hline \multirow[t]{2}{*}{ Diagnostic Test } & Yes & 12 & 18 & 6 & 33 & 69 & $<0.001^{*}$ \\
\hline & No & 28 & 34 & 80 & 48 & 190 & \\
\hline \multirow[t]{2}{*}{ BSE } & Yes & 12 & 22 & 24 & 37 & 95 & 0.067 \\
\hline & No & 29 & 30 & 62 & 44 & 164 & \\
\hline \multirow[t]{3}{*}{ How often (BSE) } & Never & 28 & 34 & 65 & 44 & 171 & $0.006^{\star}$ \\
\hline & Monthly & 4 & 16 & 14 & 23 & 57 & \\
\hline & Yearly & 8 & 2 & 7 & 14 & 31 & \\
\hline \multirow[t]{2}{*}{ CBE } & Yes & 10 & 16 & 17 & 36 & 79 & $<0.001^{*}$ \\
\hline & No & 30 & 36 & 69 & 45 & 180 & \\
\hline \multirow[t]{4}{*}{ How often (CBE) } & Never & 30 & 36 & 69 & 45 & 180 & $<0.001^{*}$ \\
\hline & Once & 2 & 2 & 8 & 2 & 14 & \\
\hline & Twice & 8 & 14 & 7 & 34 & 63 & \\
\hline & $<3$ times & 0 & 0 & 2 & 0 & 2 & \\
\hline \multirow[t]{2}{*}{ Mammography } & Yes & 0 & 10 & 8 & 33 & 51 & $<0.001^{*}$ \\
\hline & No & 40 & 42 & 78 & 48 & 208 & \\
\hline \multirow{4}{*}{$\begin{array}{l}\text { How often (mam- } \\
\text { mography) }\end{array}$} & Never & 40 & 42 & 78 & 48 & 208 & $<0.001^{*}$ \\
\hline & Once & 0 & 0 & 2 & 0 & 2 & \\
\hline & Twice & 0 & 0 & 4 & 18 & 22 & \\
\hline & $<3$ times & 0 & 10 & 2 & 15 & 27 & \\
\hline
\end{tabular}


Table 11: Knowledge of breast cancer treatment stratified by gender

\begin{tabular}{lcccc}
\hline & & Male $(\mathbf{n}=\mathbf{2 5 9})$ & Female $(\mathbf{n}=\mathbf{7 3 8})$ & p-value \\
Surgery & Yes & $119(45.9 \%)$ & $341(46.2 \%)$ & 0.942 \\
& No & $140(54.1 \%)$ & $397(53.8 \%)$ & \\
Alternative/herbal medicine & Yes & $78(30.1 \%)$ & $204(27.6 \%)$ & 0.447 \\
& No & $181(69.9 \%)$ & $534(72.4 \%)$ & \\
Prayers & Yes & $176(68.0 \%)$ & $545(73.8 \%)$ & 0.068 \\
& No & $83(32.0 \%)$ & $193(26.2 \%)$ & \\
Curable if detected early & Yes & $223(86.1 \%)$ & $610(82.7 \%)$ & 0.276 \\
\hline
\end{tabular}

Table 12: Knowledge of signs and symptoms of breast cancer stratified by gender

\begin{tabular}{|c|c|c|c|c|}
\hline & & Male $(n=259)$ & Female $(n=738)$ & p-value \\
\hline Painless lump as & Yes & $118(45.6 \%)$ & $367(49.7 \%)$ & \\
\hline sign & No & $141(54.4 \%)$ & $371(50.3 \%)$ & 0.248 \\
\hline \multicolumn{5}{|c|}{ Blood discharge from breast and what to do } \\
\hline Do nothing & & $8(3.1 \%)$ & $12(1.6 \%)$ & \\
\hline Take some drugs & & $51(19.7 \%)$ & $142(19.2 \%)$ & 0.341 \\
\hline Visit a doctor & & 200 (77.2\%) & 584 (79.1\%) & \\
\hline
\end{tabular}

Table 13: Reasons why people do not go for breast cancer screening stratified by gender

\begin{tabular}{|c|c|c|c|}
\hline & $\begin{array}{l}\text { Male } \\
n=259(26 \%)\end{array}$ & $\begin{array}{l}\text { Female } \\
n=738(74.0 \%)\end{array}$ & P-value \\
\hline It is expensive & $42(16.2 \%)$ & $113(15.3 \%)$ & \multirow{6}{*}{$0.015^{\star}$} \\
\hline Lack of awareness & $75(29.0 \%)$ & $241(32.7 \%)$ & \\
\hline It is embarrassing & 49 (18.9\%) & $150(20.3 \%)$ & \\
\hline Lack of screening equipment & $10(3.9 \%)$ & $65(8.8 \%)$ & \\
\hline Fear of a positive result & $68(26.3 \%)$ & $143(19.4 \%)$ & \\
\hline No reason & $15(5.8 \%)$ & $26(3.5 \%)$ & \\
\hline
\end{tabular}

Table 14: Beliefs of participants about breast cancer stratified by gender

\begin{tabular}{lcccc}
\hline & & Male $(\mathbf{n}=\mathbf{2 5 9})$ & Female $(\mathbf{n}=\mathbf{7 3 8})$ & p-value \\
Caused by magic and spirit & Yes & $49(18.9 \%)$ & $186(25.2 \%)$ & $0.040^{*}$ \\
& No & $210(81.1 \%)$ & $552(74.8 \%)$ & \\
Contagious & Yes & $76(29.3 \%)$ & $251(34.0 \%)$ & 0.169 \\
& No & $183(70.7 \%)$ & $487(66.0 \%)$ & \\
\hline
\end{tabular}


Table 15: Response of participants to breast cancer inclusion in school curriculum and situation in Nigeria stratified by gender

\begin{tabular}{|c|c|c|c|c|}
\hline & & Male $(n=259)$ & Female $(n=738)$ & p-value \\
\hline \multirow[t]{2}{*}{ Inclusion in the school curriculum } & Yes & $181(69.9 \%)$ & $556(75.3 \%)$ & \multirow{2}{*}{0.085} \\
\hline & No & $78(30.1 \%)$ & $182(24.7 \%)$ & \\
\hline \multirow{2}{*}{$\begin{array}{l}\text { Sufficient breast cancer awareness in } \\
\text { Nigeria }\end{array}$} & Yes & $13(5.0 \%)$ & $33(4.5 \%)$ & \multirow[b]{2}{*}{0.718} \\
\hline & No & $246(95.0 \%)$ & $705(95.5 \%)$ & \\
\hline \multirow{2}{*}{$\begin{array}{l}\text { Breast cancer a major problem in } \\
\text { Nigeria }\end{array}$} & Yes & $132(51.0 \%)$ & $302(43.5 \%)$ & \multirow{2}{*}{$0.005^{\star}$} \\
\hline & No & 127 (49\%) & $563(56.5 \%)$ & \\
\hline
\end{tabular}

tween 35 and 40 years, which is why it is crucial that the awareness of breast cancer should be at an early age. The main focus of this study was to assess knowledge, awareness, and attitudes towards breasts cancer among school teachers. The findings here in this study is in agreement with studies in some parts of the world such as Malaysia, Pakistan, Yemen, Nigeria and Saudi Arabia ${ }^{30-35}$. These results showed an overall lack of awareness and knowledge among students in universities regardless of their sex, marital status, study years, and the nature of the high school attended. It was also quite intriguing that the perceptions held by medical program students about the disease of breast cancer showed no difference with the non-medical program students. In a previous study carried out in different parts of the world such as Pakistan and Nigeria, breast cancer knowledge was observed to be limited even among nurses that are of health care professions ${ }^{35-37}$. More than half of the participants think that breast cancer is not a major problem in the country. This is also we think is what affected the awareness level of which $95.4 \%$ said that there is no sufficient breast cancer awareness (Table 15). Three hundred and sixty-seven (49.7\%) of females and 118 (45.6\%) males agreed that painless lump on a breast is a sign of breast cancer. This can be misleading information that is widely spread because of not all lumps on breast cause breast cancers. In Nigeria, according to a study report majority of breast cancer patients said that ignorance of how serious a painless lump on the breast can be is the reason why they take the longest time before they seek for medical advice ${ }^{38}$. Hence, women who are affected will tend to prolong and present late to a healthcare practitioner when they observe changes in their breasts. Some even keep it in silence and try to treat it.

Majority of the participants both male and females does not practice BSE nor CBE (Table 8). This could also imply that they have not yet received proper information on how to perform BSE. However, most of them agreed that contraceptives use increases the chances of developing breast cancer and breastfeeding decreases the risk of developing the disease (Table 7). This study shows that one of the reasons why people do not go for asymptomatic diagnosing is due to a lack of awareness (Table 13). Asymptomatic screening is essential for early breast cancer detection. Some of them indicated little or no knowledge about breast cancer risk factors even though they know about the disease (Table 13).

This highlights the critical part education can play in minimizing the delay or late presentation for a clinical check of women because they are already breast aware and are ready to take action.

Breast cancer is uncommon in those below the age of 30 , but between the age of 30 and 60 , there is a quick rise in an age-specific incidence (Table 1 ). The highest incidence rate is in the early 70 s, and there is a fiveyear survival rate following an examination which is more than $70 \%{ }^{39,40}$. Nonetheless, the overall lifetime risk of development of breast cancer is relatively 1 in 12 , which is different with age, across countries and the level of screening for the disease, also the overestimating incidence of breast cancer due to borderline pathologies detection ${ }^{39,40}$.

It might be argued that there is no specific reason as to why school teachers should know much about breast cancer. But there is the tendency of some of them carrying the wrong understanding of this disease too. However, this disease rarely develops in men, but they are significantly affected if their partners or relatives develop breast cancer. The attitudes and beliefs of some women may be influenced or shaped by their family, friends or even married partner that will tend to affect their opinion concerning risk factor modification or breast cancer screening ${ }^{41}$. For example, Norcross et al., in 1996 showed that $18.5 \%$ of women who attended a primary care practice were encouraged to participate by a friend or a male relative. In 
creating or shaping policies and public health opinions, there is a representation of both male and female sexes to balance. Therefore, it will be improper to only investigate breast cancer knowledge, awareness, and attitudes in female teachers. A previous study carried out in Switzerland assessed knowledge of breast cancer in males and females; the investigation at the end found breast knowledge was not entirely different between men and women ${ }^{41}$. Even though breast cancer is a predominantly a female disease, it is quite surprising that women do not know much better than men concerning the risks factors. A question can be asked, why are most participants aware of breast cancer, and yet they do not have much understanding of the risk factors with the signs and symptoms? The source of information the study participants indicated that they first learned about the disease had social media 78 (30.1\%) males and 148 (20.1\%) females as the highest (Table 2). Perhaps, the reason is that most information about breast cancer is gotten from the popular social media instead of physicians/health workers or professional sources, writers may influence and sensationalize this disease and concentrate anecdotally on patients that are young ${ }^{42}$. This may present inaccurate and unclear general depiction of their understanding. A few numbers of participants claimed to have had their information about breast cancer from a physician/health worker and low information grip from such professionals may indicate that the funding by the Nigerian government of health budget allocation for the year 2016 (approximately 2.7\%), although it has been increased to $4.7 \%$ in 2017 , is insufficient. Besides, even professional health workers are the source of the breast cancer information; researchers have found that the quality of such information is sometimes poor pointing to poor risk assessment, screening and mortality information ${ }^{43}$.

In our study, it was observed that $83.0 \%$ males and $87.7 \%$ of females agreed that breast cancer could be inherited (Table 7). One hundred and fifty-seven (60.6\%) males and $572(77.5 \%)$ females agreed that breastfeeding reduces the risk of breast cancer with a $p$-value of $<0.001$ (Table 7).

Ahmed et al., in 2006 observed that $35 \%$ of the nurses had a good knowledge of $40 \%$ with fair knowledge and $25 \%$ were having poor knowledge of breast cancer risk factors $^{31}$. Almost all of the nurses (99\%) were able to identify that breast cancer is not contagious and $96 \%$ said that breastfeeding does not put one at risk of developing breast cancer and the majority were positive that evil spirits had no link with breast cancer. However, the percentage of nurses who had the knowledge that overweight increases breast cancer risk was $23 \%$.
In this study, $81.1 \%$ males and $74.8 \%$ of females said that evil spirits do not cause breast cancer and $70.7 \%$ males with $66.0 \%$ females answered that breast cancer is a non-communicable disease. Notwithstanding, $64.9 \%$ and $48.2 \%$ of the men and women respectively also said that obesity is not a risk factor for breast cancer. In response to why participants have not yet gone for breast cancer screening, 75 (29.0\%) males and 241 (32.7\%) females point to lack of awareness. This result showed a statistically significant difference at a $p$ value of 0.015 (Table 13). There is a need to create more awareness about breast cancer screening methods available, and the government should please supply more.

\section{CONCLUSION}

At the end of this study, it was observed that majority of the participants know about breast cancer disease, but their knowledge on the signs and symptoms of the disease alongside carrying out screening is poor. Especially for BSE which is a very cheap lifesaving technique that needs to be upheld seriously alongside BSE, Mammography and Diagnostic test.

Although in the course of this study, it cannot be stated clearly that the breast cancer disease that was revealed is sporadic or hereditary as the majority of the participants have not been tested. So what we have to hold onto and which is the best right now is prevention. This can be achieved by creating public awareness so that the public can have good knowledge about breast cancer. It will also help the public to know what always to do because they are already breast aware. Majority of the study participants do not carry out screening tests.

The fact that they know about the disease is good, but they need to gain more in-depth knowledge about the disease. This can be achieved by the teachers making a deliberate effort to learn more about breast cancer. The government, on the other hand, can help organize seminars, workshops or as suggested by 69.9\% male and $75.3 \%$ female participants that breast cancer should be included in the school curriculum (Table 15). This will go a long way in helping the public in making informed decisions or taking actions that can help prevent breast cancer. The general public or females who are at risk can then undergo breast cancer risk management including screening, treatment choices or changes in risk lifestyle modification.

\section{RECOMMENDATION}

Teachers should make the conscious effort as to learn about breast cancer disease from reliable sources. 
In that way, they can disseminate such information to their wards or students efficiently. NonGovernmental Organizations (NGOs) can also contribute to teaching especially the females to be breast aware. The government should invest more money in the infrastructure and health personnel in that way people can have access to breast cancer screening services, and it will reduce the incidence of this disease. At the same time, the government should consider having a national screening program as well as educative programs to raise awareness on early signs and symptoms.

\section{STUDY LIMITATION}

This study population which consists of school teachers in Kaduna Metropolis is just a specific group of people in the same profession and in a particular location of Nigeria. Majority of them are educated, and this does not merely represent the general population of the country. In spite of this, the planned study was explicitly designed on school teachers because they impact lives with knowledge in the classroom and outside the classroom.

\section{COMPETING INTERESTS}

The authors state no conflict of interest.

\section{AUTHORS' CONTRIBUTIONS}

All authors participated in drafting the article and revising it critically for important intellectual content, also they all gave a final approval of the version to be submitted.

\section{REFERENCES}

1. Health OW. Breast cancer: prevention and control; 2013.

2. Oluwatosin O. Primary health care nurses' knowledge practice and client teaching of early detection measures of breast cancer in Ibadan. BMC Nursing. 2012;11:22.

3. Asuquo IM, Olajide TE. The Role of Health Education on Breast Cancer Awareness among University of Calabar Female Undergraduates. Journal of Education and Practice. 2015;6:151161.

4. McPherson K, Steel CM, Dixon JM. ABC of breast diseases. Breast cancer-epidemiology, risk factors, and genetics. BMJ (Clinical Research Ed). 2000;321:624-8. Available from: DOI 10.1136/bmj.321.7261.624.

5. (WHO) WHO. Cancer control: knowledge into action: WHO guide for effective programmes. vol. 2; 2007. .

6. Haji-Mahmoodi $M$, Montazeri A, Jarvandi S, Ebrahimi $M$, Haghighat $S$, Harirchi I. Breast self-examination: knowledge, attitudes, and practices among female health care workers in Tehran, Iran. The Breast Journal. 2002;8:222-5. Available from: DOI:10.1046/j.1524-4741.2002.08406.x.

7. Iheanacho P, Ndu A, Emenike A. Awareness of breast cancer risk factors and practiceof BSE among Female Undergraduates in University ofNigeria Enugu Campus. Open Journal of Nursing. 2013;3:147-52. Available from: DOI:10.4236/ojn. 2013.31019.

8. Doshi D. Breast self examination: knowledge, Attitude and Practice among Students in India. Indian Journal of Palliative Care. 2010;1:66-7.
9. Gwarzo U, Sabitu K, Idris S. Knowledge and practice of BSE among female undergraduate students of Ahmadu Bello University Zaria, North Western Nigeria. Annals of African Medicine. 2009;p. 55-5. Available from: Doi:10.4103/15963519.55766.

10. Omotara B, Yahya S, Amodu M, Bimba J. Awareness, Attitude and Practice of Rural Women Regarding Breast Cancer in Northeast Nigeria. Journal of Community Medicine \& Health Education. 2012;2:148. Available from: Doi:10.4172/ 2161-0711.1000148.

11. Jemal A, Siegel R, Ward E, Hao Y, Xu J, Thun MJ. Cancer statistics, 2009. CA: a Cancer Journal for Clinicians. 2009;59:225-49. Available from: DOI:10.3322/caac.20006.

12. Jemal $A$, Siegel R, Ward E, Hao Y, Xu J, Murray T. Cancer statistics, 2008. CA: a Cancer Journal for Clinicians. 2008;58:71-96. Available from: Doi:10.3322/ca.2007.0010.

13. Ly D, Forman D, Ferlay J, Brinton LA, Cook MB. An international comparison of male and female breast cancer incidence rates. International Journal of Cancer. 2013;132:1918-26. Available from: DOI:10.1002/ijc.27841.

14. Korde LA, Zujewski JA, Kamin L, Giordano S, Domchek S, Anderson WF. Multidisciplinary meeting on male breast cancer: summary and research recommendations. Journal of Clinical Oncology. 2010;28:2114-22. Available from: Doi:10.1200/jco. 2009.25.5729.

15. Basham VM, Lipscombe JM, Ward JM, Gayther SA, Ponder BA, Easton DF. BRCA1 and BRCA2 mutations in a populationbased study of male breast cancer. Breast Cancer Research. 2002;4:R2. Available from: DOI:10.1186/bcr419.

16. Ottini L, Masala G, DÁmico C, Mancini B, Saieva C, Aceto G. BRCA1 and BRCA2 mutation status and tumor characteristics in male breast cancer: a population-based study in Italy. Cancer Research. 2003;63:342-7.

17. Stein CJ, Colditz GA. Modifiable risk factors for cancer. Br J Cancer. 2004;90:299-303.

18. McCaffery K, Wardle J, Waller JO. Knowledge, attitudes, and behavioral intentions in relation to the early detection of colorectal cancer in the United Kingdom. Preventive medicine. 2003;36:525-535.

19. Miller M, Kearney N, Smith K. Measurement of cancer attitudes: a review. European Journal of Oncology Nursing 2000:4:233-45. Available from: DOI:10.1054/ejon.2000.0109.

20. Park S, Bae J, Nam BH, Yoo KY. Aetiology of cancer in Asia. Asian Pac J Cancer Prev. 2008;9:371-380.

21. Bray F, McCarron P, Parkin DM. The changing global patterns of female breast cancer incidence and mortality. Breast Cancer Research. 2004;6:229-39. Available from: DOI:10.1186/ bcr932.

22. Haraldsson $\mathrm{K}$, Loman N, Zhang QX, Johannsson O, Olsson $\mathrm{H}$, Borg A. BRCA2 germ-line mutations are frequent in male breast cancer patients without a family history of the disease. Cancer Research. 1998;58:1367-71.

23. Couch FJ, Farid LM, DeShano ML, Tavtigian SV, Calzone K, Campeau L. BRCA2 germline mutations in male breast cancer cases and breast cancer families. Nature Genetics. 1996;13:123-5. Available from: DOI:10.1038/ng0596-123.

24. Thorlacius S, Tryggvadottir L, Olafsdottir GH, Jonasson JG, Ogmundsdottir HM, Tulinius $\mathrm{H}$. Linkage to BRCA2 region in hereditary male breast cancer. Lancet. 1995;346:544-5. Available from: Doi:10.1016/s0140-6736(95)91383-1.

25. Narod SA, Dube MP, Klijn J, Lubinski J, Lynch HT, Ghadirian P. Oral contraceptives and the risk of breast cancer in BRCA1 and BRCA2 mutation carriers. Journal of the National Cancer Institute. 2002;94:1773-9. Available from: DOI:10.1093/jnci/94.23. 1773.

26. Fregene A, Newman LA. Breast cancer in sub-Saharan Africa: how does it relate to breast cancer in African-American women? Cancer. 2005;103:1540-50. Available from: DOI: $10.1002 /$ cncr.20978 
27. Ly M, Antoine M, Andre F, Callard P, Bernaudin JF, Diallo DA. Breast cancer in Sub-Saharan African women: review. Bulletin du cancer. 2011;98:797-806.

28. Wadler BM, Judge CM, Prout M, Allen JD, Geller AC. Improving breast cancer control via the use of community health workers in South Africa: a critical review. Journal of oncology. 2011;2011.

29. Mirra JM. Adamantinoma and fibrous dysplasia; 1989.

30. Al-Naggar RA, Al-Naggar DH, Bobryshev YV, Chen R, Assabri A. Practice and barriers toward breast self-examination among young Malaysian women. Asian Pacific Journal of Cancer Prevention. 2011;12:1173-8

31. Ahmed F, Mahmud S, Hatcher J, Khan SM. Breast cancer risk factor knowledge among nurses in teaching hospitals of Karachi, Pakistan: a cross-sectional study. BMC Nursing. 2006;5:6.

32. Yadav P, Jaroli DP. Breast cancer: awareness and risk factors in college-going younger age group women in Rajasthan. Asian Pacific Journal of Cancer Prevention. 2010;11:319-22.

33. Sait WA, Al-Amoudi SM, Tawtai DA, Abduljabbar HS. The knowledge of breast cancer among young Saudi females. Saudi Medical Journal. 2010;31:1242-4.

34. Karayurt O, Ozmen D, Cetinkaya AC. Awareness of breast cancer risk factors and practice of breast self examination among high school students in Turkey. BMC Public Health. 2008;8:359-67. Available from: Doi:10.1186/1471-2458-8-359.

35. Ahmed F, Mahmud S, Hatcher J, Khan SM. Breast cancer risk factor knowledge among nurses in teaching hospitals of Karachi, Pakistan: a cross-sectional study. BMC Nursing.
2006;5:6. Available from: Doi:10.1186/1472-6955-5-6.

36. PhD RNMC, MPH CRF. Perceptions about breast cancer among college students: implications for nursing education. Journa of Nursing Education. 2005;44:257.

37. Odusanya OO, Tayo OO. Breast cancer knowledge, attitudes and practice among nurses in Lagos, Nigeria. Acta Oncologica (Stockholm, Sweden). 2001;40:844-8. Available from: Doi:10 1080/02841860152703472.

38. Ukwenya AY, Yusufu LD, Nmadu PD, Garba ES, Ahmed A. Delayed treatment of symptomatic breast cancer: the experience from Kaduna, Nigeria. South African Journal of Surgery. 2008;46.

39. Group EEBCTC. Tamoxifen for early breast cancer: an overview of the randomised trials. The Lancet. 1998;351:1451-1467. null.

40. Cancer in Ireland t. Incidence, mortality, treatment and survival. In: Report of the National Cancer Registry. National Cancer Registry Board; 2001. null.

41. Chamot E, Perneger TV. Menś and womenś knowledge and perceptions of breast cancer and mammography screening. Preventive medicine. 2002;34:380-385.

42. Marino C, Gerlach KK. An analysis of breast cancer coverage in selected womenś magazines, 1987-1995. American Journa of Health Promotion. 1999;13:163-70. Available from: Doi: 10.4278/0890-1171-13.3.163.

43. Slaytor EK, Ward JE. How risks of breast cancer and benefits of screening are communicated to women: analysis of 58 pamphlets. BMJ (Clinical Research Ed). 1998;317:263-4. Available from: DOI:10.1136/bmj.317.7153.263. 